\title{
宁夏沙坡头国家级自然保护区动物资源的消长
}

\author{
刘迺发 黄族豪 \\ (兰州大学生命科学学院, 兰州 730000) \\ 吴洪斌＼cjkstart刘荣国＼cjkstart郝耀明 \\ (宁夏沙坡头国家级自然保护区管理所，中卫 751700)
}

摘要：1986 1987 年首次全面调查了宁夏沙坡头自然保护区的动物种类及其数量。为了解 1986 年以来保护区动 物资源的消长变化及其原因, 1998 1999 年又 4 次调查了该地脊椎动物种类及数量。10 多年来沙坡头自然保护区 的动物资源变化明显。1999 年国家重点保护动物比 1986 年增加 7 种,已达 19 种,其中国家 I 类保护种类 3 种, II 类保护种类 16 种。鸟类增加 35 种, 其中宁夏新记录 11 种;兽类新增 3 种;两栖类和爬行类各减少 2 种; 鼠类减少 3 种。1999 年与 1986 年相比, 湿地景观水鸟种类和数量显著增加, 村庄农田景观、荒漠景观和固沙林景观鸟类种类 和数量减少。环境指示种类纵纹腹小鸮 (Athene noctua)、黑顶麻雀 (Passer ammodendri)、树麻雀 (Passer montanus)、 凤头百灵 (Galerida cristata) 、大杜鹃 (Cuculus canorus)、山斑鸭 (Streptopelia orientalis) 等种群数量明显减少。鼠类不 但种类减少, 数量也明显下降。影响动物种类、数量发生变化的主要因素是由于病虫害、人类对土地开发利用和生 产活动引起的防风固沙林面积减少; 地下水位下降; 水环境污染严重, 水质变坏和富营养化; 草甸、草原覆盖度下 降 草场退化;农田和鱼塘面积扩大。

关键词: 宁夏, 沙坡头, 保护区, 动物, 种类, 数量, 消长

中图分类号:Q958 文献标识码: A 文章编号 : 1005-0094(2002)02-0156-07

\section{Growth and decline of animal resource in Shapotou National Nature Re- serve , Ningxia}

LIU Nai-Fa , HUANG Zu-Hao

College of Life Sciences, Lanzhou University, Lanzhou 730000

WU Hong-Bin , LIU Rong-Guo , HAO Yao-Ming

Ningxia Shapotou National Nature Reserve, Zhongwei, Ningxia 751700

Abstract : The Shapotou National Nature Reserve, situated on the southeastern edge of the Tenggeli Des-
ert, is a nature reserve for desert and semi-desert eco-systems. Animal species and their abundances in
the reserve were investigated during $1986 \sim 1987$. In order to know the growth and decline of animal re-
source in the reserve since 1986 , we investigated animal species, their amount and environmental condi-
tions during $1998 \sim 1999$. Nineteen protected animal were recorded in $1998 \sim 1999$, among which three
species are class I protected species and the others belong to class II protected species. In comparison
with $1986 \sim 1987$, the species protected by law in China increased by seven species. Thirty-five addition-
al species of birds were recorded, among which eleven species were new records for Ningxia. Three addi-
tional species of mammals were recorded, but three species of rodent were not re-encountered in the sec-
ond survey. Two species of amphibian and reptiles also were not re-encountered. Comparing animal a-
bundances between $1986 \sim 1987$ and $1998 \sim 1999$, bird numbers in wetland habitat increased significant-
ly, but those in village farmland, desert and sand-stabilization forest decreased. Specifically, the amount
of bird as environmental indicator, such as Athene noctua, Passer ammodendri, Passer montanus, Galeri-
da cristata, Cuculus canorus, and Streptopelia orientalis , were significantly reduced. Not only did rodent 
species richness decrease, but numbers also declined markedly. The main factors which led to the growth and decline of animal species and their amount in Shapotou National Nature Reserve were : (1) the destruction of sand-stabilization forest ruined through economic action of human beings and plant diseases ;

(2) falling groundwater level, serious wetland pollution and the addition of abundant nutrients to water ; ( 3 ) degradation of meadow and grassland ; (4) enlargement of the area of farms and ponds.

Key words : Ningxia , Shapotou Nature Reserve , animal resources ,species ,amount ,growth and decline

自然保护区是宝贵的物种基因库（Primack， 1993 ) 我国重点保护动物主要集中分布于各自然 保护区内。国内对单种( 龙勇诚等,1996;于孝臣 等 2000 ;喻晓钢等,2001; 赵文双等,2001) 或某类 (李晓鸿等, 1999; 吕顺清,杨大同,1999 ;苏化龙等， 2000 ;杨岚, 潘汝亮, 1985) 动植物的现状和保护研究 较多,但有关自然保护区或地区动物资源消长变化 及原因的研究工作较少。

宁夏沙坡头自然保护区是我国北方荒漠半荒漠 生态系统类型自然保护区，成立于 1984 年 9 月， $1986 \sim 1987$ 年对保护区进行了首次全面的综合考 察,1994 年 4 月经国务院批准为国家级自然保护 区。为了解沙坡头地区动物资源的消长变化,1998 $\sim 1999$ 年我们又对保护区的脊椎动物进行了多次 调查研究。本文在这些调查的基础上分析了 1986 年以来沙坡头保护区动物种类、数量的消长变化趋 势和原因，为保护区制定生物多样性保护对策提供 基础资料和科学依据。

\section{1 研究地区}

沙坡头位于宁夏中卫县西部, 其北缘腾格里沙 漠, 南至黄河北岸, 东起高鸟堆, 西至孟家湾。地处 $37^{\circ} 36^{\prime} 15^{\prime \prime} \sim 37^{\circ} 36^{\prime} 30^{\prime \prime} \mathrm{N}, 105^{\circ} 0^{\prime} 55^{\prime \prime} \sim 105^{\circ} 11^{\prime} 15^{\prime \prime} \mathrm{E}$ ， 总面积约 $13400 \mathrm{hm}^{2}$, 海拔 $1200 \sim 1500 \mathrm{~m}$ 。

气候属荒漠草原气候, 年平均温度 $9.7^{\circ} \mathrm{C}$, 年平 均降水量 $304.2 \mathrm{~mm}$, 年蒸发量 $3000 \mathrm{~mm}$ 。年起风沙 时数 $2900 \mathrm{~h}$, 占全年时数的 $10.3 \%$ 。降水少、蒸发 量大、风沙多的气候环境影响植物的生长, 植物生长 期 150 180 天, 自然植被矮小而稀疏, 以灌木、半灌 木沙生植物为主。随着人类对荒漠的改造, 出现了 乔木和灌木结合的人工植被, 但防风固沙林面积正 日益减少。

\section{2 调查方法}

\section{1 乌类调查方法}

1999 年与 1986 年鸟类种类和数量的调查方法
相同, 都以样线法进行, 以景观为背景, 包括湿地、固 沙林、荒漠和村庄农田景观, 其中湿地景观 8 条样 线, 荒漠景观 6 条, 村庄农田景观 8 条, 固沙林景观 是重点, 共设 19 条样线。沿样线以 $3.0 \mathrm{~km} / \mathrm{h}$ 的速 度前进，记录起止时间和样线两侧各 $50 \mathrm{~m}$ 范围内鸟 的种类和数量。鸟类数量以只 $/ \mathrm{km}$ 表示。

\section{2 鼠类种类和数量调查方法}

1999 年和 1986 年鼠类种类和数量的调查方法 也一样, 都采用铗捕法, 布铗面积 $0.4 \sim 0.6 \mathrm{hm}^{2}$,也 选用鸟类调查的四种景观布铗。1986 年布铗总数 1072 个,1999 年 2620 个。鼠类的数量用铗捕率表 示, 种数铗捕率以捕获的各种鼠的个体数/铗日数计 算。

\section{3 结果}

\section{1 保护动物种类及数量变化}

宁夏沙坡头国家级自然保护区被列入国家重点 保护野生动物名录的种类有 19 种,其中 I 类保护的 3 种, II 类保护 16 种 (表 1)。1986 1987 年调查记 录 12 种, 1998 1999 年记录 18 种, 1986 1987 年 调查记录的大天鹅 (Cygnus cygnus) 在 1998 1999 年没有发现, 1998 1999 年增加了 7 种。

1986 年只有荅( Milvus korschun)、大鵟( Buteo hemilasius)、红隼 (Falco tunnunculus) 和纵纹腹小鸮 (Athene noctua) 的夏季数量调查, 所以只用 1999 年 夏季这 4 种动物数量与之比较。荒漠景观和湿地景 观 1999 年 4 种保护动物数量显著增加, 而固沙林景 观和村庄农田景观的数量有所减少。单种数量, 纵 纹腹小鸮的种群数量减少最多 (表 2)。

\section{2 两栖爬行类种类变化}

1986 年两栖类有 3 种,爬行类有 5 种; 1999 年 两栖类只发现 1 种花背蟾蜍 (Bufo raddei)。未见林 蛙 (Rana temporaia) 和黑斑蛙 (Rana nigromacula$t a)$ 。1999 年爬行类只见密点麻蜥 (Eremias multiocellata)、荒漠沙蜥 (Phrynocephalus przewalskii) 和虎 
表 1 沙坡头自然保护区国家重点保护动物名录

Table 1 State protected animal species in Shapotou Nature Reserve

种类

Species

黑鹳 Ciconia nigra

金雕 Aquila chrysaetos

玉带海雕 Haliaeetus leucoryphus

大天鹅 Cygnus cygnus

茑 Milvus korschun

大鵟 Buteo hemilasius

白尾䍃 Circus cyaneus

鹗 Pandion haliaetus

红隼 Falco tunnunculus

灰背隼 Falco columbarius

纵纹腹小鸮 Athene noctua

雕鸮 Bubo bubo

短耳鸮 Asio flammeus

长耳鸮 Asio otus

䓙羽鹤 Anthropoides virgo

荒漠猫 Felis bieti

猞猁 Lynx lynx

岩羊 Pseudois nayaur

鹅喉羚 Gazella subgutturosa
保护级别 class

I

I

I

II

II

II

II

II

II

II

II

II

II

II

II

II

II

II

II

斑游蛇 ( Natrix tigrina) , 而花条蛇 ( Psammophis lineolatus) 和腹蛇 (Agkistrodon halys) 没有发现。而且 1999 年 2 种蚚蜴的数量明显少于 1986 年。

\section{3 乌类种类和数量变化}

3.3.1 鸟类种类变化 鸟类是沙坡头荒漠生态系 统中最重要的一个类群, 种类多、分布广。两次调查 都比较系统。1986 年调查鸟类有 15 目 35 科 100 种 (张迎梅,王香亭,1990)。1999 年鸟类种数比 1986 年新增 35 种，它们是凤头䲽讹鳥 (Podiceps cristatus)、 白鹭 (Egretta garzetta)、大麻鳽 (Botaurus stellaris)、 白眼潜鸭 (Aythya nyroca)、针尾鸭 (Anas acuta)、赤 嘴潜鸭 ( Netta rufina)、白尾鹞 (Circus cyaneus)、鹗 (Pandion haliaetus)、白胸苦恶鸟 (Amaurornis phoenicurus)、白腰草璚（Tringa ochropus）、黑尾鸥 (Larus crassirostris)、黄头粦鸰 (Motacilla citreola)、红嘴山鸦 (Pyrrhocorax pyrrhocorax)、小嘴乌鸦（Corvus coro$n e$ )、黑尾地鸦 (Podoces hendersoni)、树翏鳥 (Anthus hodgsoni)、黄眉柳茑 (Phylloscopus inornatus)、褐柳 莺( Phylloscopus fuscatus)、大山雀 (Parus major)、蓑 羽鹤（Anthropoides virgo）、斑豚木鸟( Picoides major) 、红喉姬鹃 (Ficedula parva)、夜鹭 (Nycticorax nycticorax)、黑喉石即（Saxicola torquata）、池路

(Ardeola bacchus)、灰背隼 (Falco columbarius)、泽璚 ( Tringa stagnatilis)、彩璚 ( Rostratula benghalensis)、 鱼鸥 (Larus ichthyaetus)、草地翏鳥 (Anthus pratensis)、 荒漠伯劳 (Lanius isaballinus)、北灰暡( Muscicapa latirostris)、太平鸟(Bombycilla garrulus)、玉带海雕 (Haliaetus leucoryphus)、中滳 (Numenius phaeopus)。后 11 种是宁夏新记录。

但是在上述种类增加的同时,1986 1987 年记 录的鸟类中有 19 种在 1999 年的调查中没有发现， 它们是大天鹅、花脸鸭 (Anas formosa) 、鹊鸭 (Bucephala clangula)、普通秧鸡 (Rallus aquaticus)、 雨燕 (Apus apus)、黑卷尾 (Dicrurus macrocercus)、发 冠卷尾 (Dicrurus hottenttotus)、红点颏 ( Luscinia calliop )、黄腰柳莺 (Phylloscopus proregulus)、红胁兰尾 鸲( Tarsiger cyanurus)、漠莺 (Sylvia nana) 、文须雀 (Panurus biarmicus)、灰头卅 (Emberiza spodocepha$l a) 、$ 芦幽 (Emberiza schoeniclus)、漠雀 (Rhodopechys mongolica)、长尾雀( Uragus sibiricus)、寒鸦 (Corvus dauricus)、燕衍 (Glareola maldivarum) 和白喉红尾鸲 (Phoenicurus schisticeps)。

3.3.2 鸟类数量变化 在 1986 1987 年调查中只 统计了 1986 年夏季鸟的数量, 1998 1999 年虽然 调查了各季鸟类的数量, 但可与之比较的只有 1999 年夏季鸟类数量调查结果。1986 年夏和 1999 年夏 只有 26 种鸟是两年重复统计的,占沙坡头 1986 年 夏季统计鸟类种数的 $59.1 \%$ 。依这 26 种的数量调 查结果, 1999 年夏季平均每公里遇见的鸟类数量在 任何景观中都少于 1986 年 (图 1)。荒漠景观 1986 年平均每公里遇见鸟类数量是 1999 年的 2.8 倍, 湿 地景观是 1.3 倍, 固沙林景观是 2.5 倍, 村庄农田景 观是 1.9 倍 (表 3 )。

1999 年和 1986 年各景观每公里遇见鸟的数量是 另一个可比的量化指标。湿地景观 1999 年每公里遇 见乌 126.2 只,高于 1986 年的 59.4 只, 是其 2.2 倍。 其余 3 个景观 1986 年每公里遇见乌数量均高于 1999 年, 固沙林景观 1986 年 (21.64 只/ $\mathrm{km}$ ) 是 1999 年 $(18.73$ 只 $/ \mathrm{km})$ 的 1.16 倍, 荒漠景观 1986 年 $(43.45$ 只 $/ \mathrm{km})$ 是 1999 年 $(18.82$ 只 $/ \mathrm{km})$ 的 2.31 倍，村庄农 田景观 1986 年 (52.72 只 $/ \mathrm{km}$ ) 是 1999 年 (30.64 只/ $\mathrm{km})$ 的 1.72 倍。上述说明沙坡头自然保护区固沙林 景观, 荒漠景观, 村庄农田景观乌类数量 13 年明显下 降，而湿地景观鸟类数量显著增加 (图 2)。 
表 21999 年和 1986 年沙坡头自然保护区 4 种保护动物数量比较(只/ $\mathbf{k m}$ )

Table 2 Comparison of the amount of four protected animals between 1999 and 1986 in Shapotou Nature Reserve (Ind. / km)

\begin{tabular}{|c|c|c|c|c|c|c|c|c|}
\hline \multirow[t]{2}{*}{ 种类 Species } & \multicolumn{2}{|c|}{$\begin{array}{c}\text { 荒漠景观 } \\
\text { Desert }\end{array}$} & \multicolumn{2}{|c|}{$\begin{array}{l}\text { 湿地景观 } \\
\text { Wetland }\end{array}$} & \multicolumn{2}{|c|}{$\begin{array}{c}\text { 固沙林景观 } \\
\text { Fixing sand forest }\end{array}$} & \multicolumn{2}{|c|}{$\begin{array}{l}\text { 村庄农田景观 } \\
\text { Village farmland }\end{array}$} \\
\hline & 1986 & 1999 & 1986 & 1999 & 1986 & 1999 & 1986 & 1999 \\
\hline 鸽 Milvus korschun & & & & 1.13 & 1.10 & 0.74 & & \\
\hline 大鵟 Buteo hemilasius & 0.26 & 0.33 & 0.10 & & & 0.16 & & \\
\hline 红隼 Falco tunnunculus & 0.33 & 0.67 & & 0.50 & 0.57 & 0.11 & & \\
\hline 纵纹腹小鸮 Athene noctua & & & & & 0.71 & & 0.36 & 0.13 \\
\hline 总计 Total & 0.59 & 1.00 & 0.10 & 1.63 & 2.38 & 1.01 & 0.36 & 0.13 \\
\hline
\end{tabular}

表 31999 年和 1986 年沙坡头自然保护区夏季 26 种鸟类数量比较 (只/ $\mathbf{k m}$ )

Table 3 Comparison of the amount of 26 bird species between 1999 and 1986 in summer in Shapotou Nature Reserve (Ind. /km)

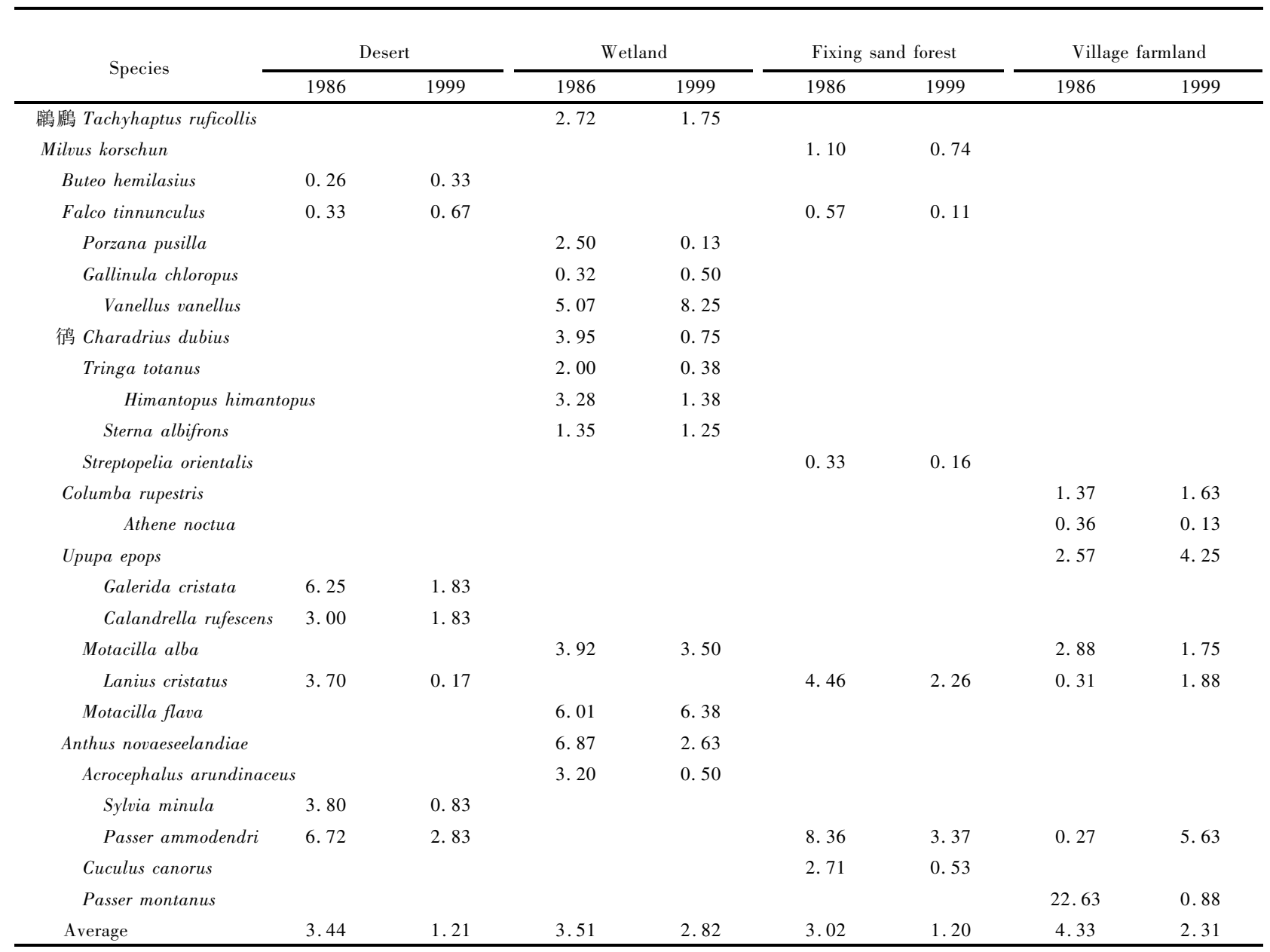

\section{4 哺乳类种类及种群数量变化}

\subsection{1 种类变化 $1986 \sim 1987$ 年调查哺乳类有 5} 目,11科,19 种。1998 1999 年调查, 哺乳类新增 3 种，它们是䴤鼠 (Ondatra zibethica)、鹅喉羚 (Gazella subgutturosa) 和猞猁 (Lynx lynx)。但是有 3 种鼠类: 长尾仓鼠( Cricetulus longicaudatus)、长爪沙鼠( Meriones unguiculatus) 和小家鼠( Mus musculus) 在 1999
年没有捕到。

3.4.2 数量变化 啮齿类是荒漠生态系统中种类 多, 具有代表性的组成部分, 它们的数量变化最能反 映荒漠生态系统的状况。

1999 年与 1986 年鼠类的数量相比,1999 年子 午沙鼠 (Meriones meridianus)、三趾跳鼠 (Dipus sagit$t a$ )、黑线仓鼠 (Cricetulus barabensis) 单种铗捕率高 
表 41986 和 1999 年沙坡头自然保护区鼠类及数量 ( 铗捕率)

Table 4 Capture of rodents in Shapotou Nature Reserve in 1986 and 1999 (Capture rate)

\begin{tabular}{|c|c|c|c|c|}
\hline \multirow{2}{*}{$\begin{array}{l}\text { 种 类 } \\
\text { Species }\end{array}$} & \multicolumn{2}{|c|}{1986} & \multicolumn{2}{|c|}{1999} \\
\hline & $\begin{array}{l}\text { 数量 } \\
\text { No. }\end{array}$ & $\begin{array}{c}\text { 铗捕率 } \\
\text { Capture rate }\end{array}$ & $\begin{array}{l}\text { 数量 } \\
\text { No. }\end{array}$ & $\begin{array}{c}\text { 铗捕率 } \\
\text { Capture rate }\end{array}$ \\
\hline 三趾跳鼠 Dipus sagitta & 4 & 0.37 & 14 & 0.53 \\
\hline 荒漠毛蹠鼠 Phodopus roborovskii & 14 & 1.31 & 5 & 0.19 \\
\hline 长尾仓鼠 Cricetulus longicaudatus & 52 & 4.85 & & \\
\hline 长爪沙鼠 Meriones unguiculatus & 7 & 0.65 & & \\
\hline 子午沙鼠 Meriones meridianus & 14 & 1.31 & 67 & 2. 56 \\
\hline 小家鼠 Mus musculus & 13 & 1.21 & & \\
\hline 褐家鼠 Rattus norvegicus & & & 1 & 0.04 \\
\hline
\end{tabular}

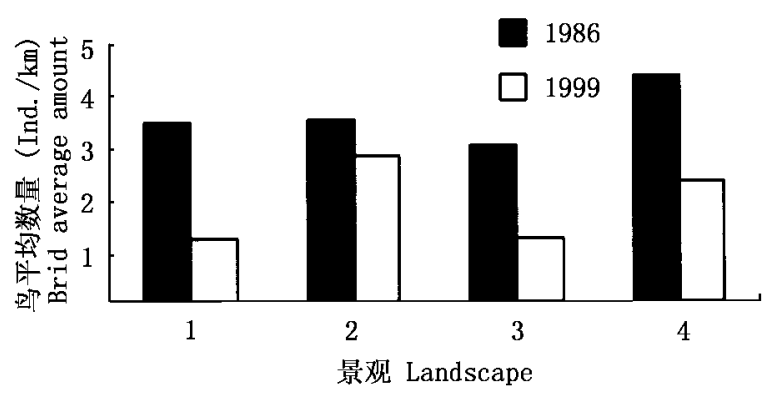

图 1 沙坡头保护区 1986 年和 1999 年夏季 26 种鸟平均数 量

Fig. 1 Frequency of common bird species in Shapotou Nature Reserve in the summer of 1986 and 1999

1. 荒漠景观 Desert ,2. 湿地景观 Wetland ,3. 固沙林景观 Fixing sand forest 4 . 村庄农田景观 Village farmland

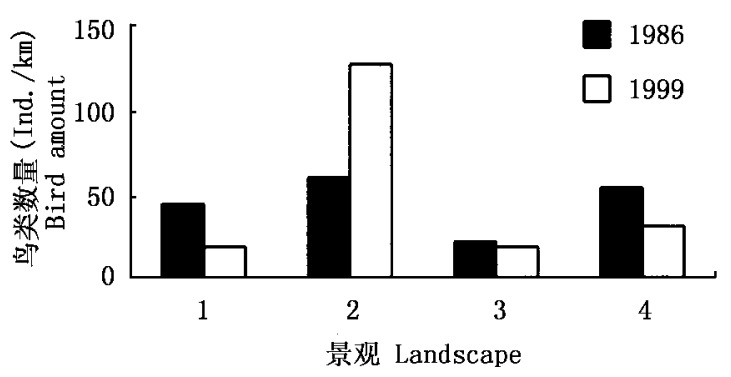

图 2 沙坡头保护区 1986 年和 1999 年夏季不同景观每公里 遇见乌的数量

Fig. 2 Frequency of brid species in Shapotou Nature Reserve in the summer of 1986 and 1999

1. 荒漠景观 Desert ,2. 湿地景观 Wetland ,3. 固沙林景观 Fixing sand forest, 4 . 村庄农田景观 Village farmland

于 1986 年。1986 年五趾跳鼠( Allactaga sibirica)、 荒漠毛蹠鼠 ( Phodopus roborovskii) 单种铗捕率则高 于 1999 年 (表 4 )。虽然部分鼠类 1999 年的数量高 于 1986 年,但总的鼠类数量下降。

\section{4 讨论}

\section{1 动物种类、数量变化的原因}

4.1.1 保护动物种类和数量的变化 1999 年增加 的重点保护鸟都是旅鸟, 迁飞途中在保护区内短暂 停息。鸟类迁飞虽然有一定的路线，但这是“面”而 不是 线”。天气会影响鸟类迁飞, 使它们偏离迁飞 路线, 出现在沙坡头自然保护区。鹗 (Pandion haliaetus)、玉带海雕 (Haliaeetus leucoryphus) 和蒿羽鹤 (Anthropoides virgo) 都与湿地关系密切, 鹗是水中捕 鱼的鸟,玉带海雕捕食鱼类和兔子, 㝨羽鹤是典型的 湿地鸟, 而且以鱼、水草等为食。沙坡头自然保护区 的马场湖、高墩湖、小湖乃至黄河等湿地对这些鸟类 富有吸引力, 加之保护区内开辟鱼塘和湖泊养鱼, 为 食鱼鸟提供了食物。这是沙坡头自然保护区重点保 护鸟类增加的根本原因。保护动物中纵纹腹小鸮数 量下降最多。依 1986 年夏季在沙坡头收集的 128 块小鸮吐出的食物团块分析, 其食物中鼠类占 81 . $44 \%$,余为蚚蜴。刘迺发 (1993) 报道民勤荒漠小鸮 的食物主要是鼠类和蚚蜴。沙坡头地区 1999 年鼠 类数量比 1986 年减少 $72.61 \% \sim 75.63 \%$,蚚蜴也 明显减少, 食物的丰富程度控制了小鸮的数量, 其种 群数量随食物丰富度下降而下降。

沙坡头保护区增加的保护兽类 2 种,鹅喉羚和 猞猁。这两种动物在保护区相邻的干塘就有分布, 出现在保护区是顺理成章的。猞猁的出现还与保护 区兔子数量多有关, 1999 年 8 月在荒漠和人工固沙 林中统计 26 条 1 公里的样带, 遇见兔子 12 只, 平均 每公里遇见 0.46 只。

\subsection{2 两栖类种类减少 1999 年调查没有发现的}


黑斑蛙和林蛙都是蛙科的种类。它们与蟾蜍不同， 无论幼体还是成体都要求水体清洁，水体污染对它 们的危害是致命的。沙坡头自然保护区的水污染主 要来自两个方面: 1986 年以来鱼塘和湖泊大量高密 度养鱼, 没有消耗的剩余饵料、鱼的粪便造成水体富 营养化, 藻类大量滋生, 水体变绿, 水中溶解氧减少, 水质变坏。农田大量使用农药和化肥，残余的农药、 化肥随农田灌溉水流入鱼塘和湖泊，造成水体污染， 水质变坏。水体污染造成两栖类数量和种类减少已 是世界性的问题（吕顺清，杨大同，1999），应引起注 意, 采取措施, 拯救蛙类。

4.1.3 鸟类种类和数量的变化 1999 年增加的 35 种鸟中有 31 种是旅鸟和夏候鸟, 占 $86.11 \%$ 。减少 的 19 种鸟中, 16 种是旅鸟或夏候鸟, 占 $84.22 \%$ 。 这类鸟增加和减少的原因之一与迁徙动态有关。原 因之二是由于湖泊养鱼大面积开辟鱼塘, 现有鱼塘 面积已达 $210.9 \mathrm{hm}^{2}$,占保护面积的 $1.54 \%$,为鸥 类、鹭类和璚类提供了栖息场所和充分的食物，使其 种类和数量增加。在增加的种类中有 16 种主要或 部分以鱼为食, 占增加种类的 $44.44 \%$ 。原因之三 是人工固沙林大面积发生虫害, 大山雀、豚木鸟迁来 受食。减少的种类中的寒鸦原是留居的繁殖鸟, 营 巢在定北墩长城遗址的洞内, 由于人类对长城遗址 的利用和破坏,使其失去了营巢生境，在保护区消 失。发冠卷尾和黑卷尾是沙坡头人工固沙林营巢的 夏候鸟，因天牛危害人工林，树木死亡被伐，这 2 种 鸟在保护区消失。因此，鸟类种类的增加或减少无 不与环境改变有关, 人类活动和天牛对固沙林的危 害改变了乌类群落的组成, 可以预测随杨树固沙林 进一步枯死和消失还有一些依赖人工林的鸟类将从 保护区消失。

1999 年荒漠景观、固沙林景观和村庄农田景观 鸟类数量减少, 主要受荒漠固有种风头百灵、黑顶麻 雀和人类伴生种麻雀的减少影响。凤头百灵是典型 的荒漠草原鸟类。但 10 多年来，几大片原本长势很 好的荒漠草原被固沙林替代了, 如荒草湖一带, 可利 用的栖息环境减少,凤头百灵数量下降。黑顶麻雀 是典型的荒漠森林、灌丛鸟类。依 1986 年调查, 它 们营巢在人工固沙林接近树底部的枝权间。由于天 牛危害, 林木枯死, 黑顶麻雀失去了稳定的营巢环 境, 其繁殖成功率下降, 种群数量下降。此外 13 年 来人工固沙林面积减少 $468 \mathrm{hm}^{2}$,栖息地面积的减
少是黑顶麻雀数量下降的又一原因。麻雀是与人类 伴生的村庄农田景观的代表鸟类, 它们营巢于屋檐 下或墙洞中。近些年农村经济发展, 农民生活水平 提高, 大多数农民推土房, 盖砖房, 麻雀在农村失去 了合适的营巢环境, 种群数量下降。

1999 年湿地景观每公里遇见鸟的数量显著高 于 1986 年。1999 年湿地鸟类数量增加的主要原因 是家燕 (Hirundo rastica) 、大麻鳽、斑嘴鸭 (Anas poecilorhyncha 、苍鹭 (Ardea cinerea) 4 种鸟数量猛增, 它们的数量占湿地鸟类每公里遇见数的 $56.51 \%$ 。 1986 年夏季调查时这几种鸟在湿地景观没有统计 到(刘逎发,1990)。严格地说家燕不是湿地鸟, 但 它们集大群跟随在湿地放牧的羊群之后, 捕食羊冲 起的昆虫, 在小湖湿地大群达百余只。大麻鳽、苍鹭 和斑嘴鸭是典型湿地鸟, 大量养鱼为它们提供了丰 富的食物, 使其数量增加。由于上述 4 种鸟数量增 加, 使湿地景观鸟类数量 1999 年高于 1986 年。

4.1.4 鼠类种类和数量的变化 1999 年鼠类新增 一种㮎鼠，这种从国外引入人工饲养的经济动物，从 饲养场中逃出, 进入野外, 现分布很广。什么时间、 通过什么途径进入保护区，目前还不清楚。

1999 年有 3 种鼠没有捕到, 其中小家鼠是人类 伴生的鼠类, 1986 年铁路固沙林场的人工林和荒漠 两种景观均有分布, 但更多分布于靠近房屋的林中。 长尾仓鼠 1986 年主要捕于靠近房屋的人工固沙林 和砾石荒漠。天牛危害使大量杨树枯死, 林地被旺 为农田, 原来的土房改建成砖房和楼房, 环境的改变 使上述两种鼠从群落中消失。长爪沙鼠1 1986 年数 量就很少(刘迺发, 1991)。

鼠类数量减少的原因主要有三: (1) 优势种长 尾仓鼠消失, 1986 年总铁捕率为 4.85 , 而 1999 年为 0 ;(2) 环境变化, 尤其是固沙林改为农田, 灌溉农田 鼠类很少, 1999 年农田果园中, 捕到 2 种鼠, 黑线仓 鼠共捕到 4 只, 大家鼠夏季只捕到 1 只; (3) 1999 年 种群性比失调, 春季子午沙鼠雄: 雌 $=1: 0.5$, 三趾 跳鼠雄: 雌 $=1: 0.75$ 。1999 年夏季子午沙鼠雄: 雌 $=24: 1$, 五趾跳鼠雄: 雌 $=3: 1$, 三趾跳鼠雄: 雌 $=3: 1$, 另外没有捕到荒漠毛蹠鼠的雌鼠。什么 原因导致种群性比失调不清楚, 而性比失调对鼠类 的繁殖影响很大, 尤其使其生殖力下降, 致使种群数 量下降。

综上所述，影响沙坡头自然保护区动物资源消 
长的因素是: (1) 防风固沙乔木林面积减少, 林木衰 败; (2)地下水位下降, 水环境污染严重, 水质变坏 和富养化; (3) 草甸、草原覆盖度下降, 草场退化; (4) 城镇化、农田和鱼塘面积扩大, 改变了自然和人 工景观的生物群落结构。

\section{参考文献}

李晓鸿, 黄晨翔, 王宏, 何柏宏, 1999. 甘肃白水江国家级自 然保护区食肉兽类的现状与保护. 见: 中国动物科学研 究. 北京: 中国林业出版社, 649 653

刘迺发, 常城, 1990. 宁夏沙坡头繁殖鸟类群落及演替研究.

兰州大学学报(自然科学版), 26(4) : 95 101

刘迺发, 常城, 1991. 沙坡头地区鼠类的密度和危害. 见: 中 国科学院兰州沙漠研究所沙坡头沙漠科学研究站( 编), 腾格里沙漠沙坡头地区流沙治理研究 (二). 银川: 宁夏 人民出版社, 120 125

刘迺发, 1993. 甘肃民勤治沙站小鸮食物的研究. 野生动物, (3) : $12 \sim 13$

龙勇诚, 柯瑞戈, 钟泰, 肖李, 1996. 滇金丝猴 (Rhinopithecus bieti) 现状及其保护对策研究. 生物多样性, 4(3): 145
152

吕顺清, 杨大同, 1999. 我国澜沧江流域两栖类多样性及人 文因素对其的影响. 见: 中国动物科学研究. 北京: 中国 林业出版社, $461 \sim 466$

苏化龙, 林英华, 李迪强, 钱法文, 2000。中国鹤类现状及其 保护对策. 生物多样性, 8(2): 180 191

于孝臣, 张梦利, 梅庆明, 王晓峰, 安春林, 2000. 中国东方白 鹳种群现状及保护对策. 野生动物, 21(3): 12 13

杨岗, 潘汝亮, 1985. 西双版纳 (云南省) 茶林及橡胶林区乌 类调查. 动物学研究, 6(4) : 353 360

喻晓钢, 简基伦, 李文秀, 郑雄, 王肖华, 钟开国, 2001. 九顶 山野生猕猴桃资源分布及保护. 中国野生植物资源, 20 (1) : $36 \sim 37$

张迎梅, 王香亭, 1990. 宁夏沙坡头保护区乌类区系与沙漠 治理. 兰州大学学报(自然科学版), 26(3):88 98

赵文双, 王可有, 张树浩, 2001. 辽宁省原蝔资源现状及保护 管理对策. 野生动物, 22(2): 45 46

Primack R B, 1993. Essential of Conservation Biology. Sinauer Associates Inc, Sunder Land, Massadusetts U. S. A. 1 511 